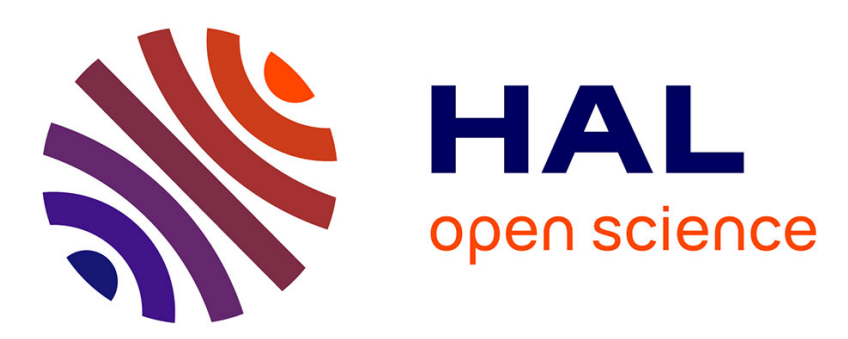

\title{
A Collaborative Planning Model to Coordinate Mining and Smelting Furnace
}

Fenemedre Qaeze, Romain Guillaume, Caroline Thierry

\section{To cite this version:}

Fenemedre Qaeze, Romain Guillaume, Caroline Thierry. A Collaborative Planning Model to Coordinate Mining and Smelting Furnace. 16th IFIP Working Conference on Virtual Enterprises: Risks and Resilience of Collaborative Networks (PRO-VE 2015), IFIP International Federation for Information Processing, Oct 2015, Albi, France. pp.557-565, 10.1007/978-3-319-24141-8_52 . hal-01303831v2

\section{HAL Id: hal-01303831 \\ https://hal.science/hal-01303831v2}

Submitted on 18 Apr 2016

HAL is a multi-disciplinary open access archive for the deposit and dissemination of scientific research documents, whether they are published or not. The documents may come from teaching and research institutions in France or abroad, or from public or private research centers.
L'archive ouverte pluridisciplinaire HAL, est destinée au dépôt et à la diffusion de documents scientifiques de niveau recherche, publiés ou non, émanant des établissements d'enseignement et de recherche français ou étrangers, des laboratoires publics ou privés.

\section{(c)(1)}

Distributed under a Creative Commons Attribution| 4.0 International License 


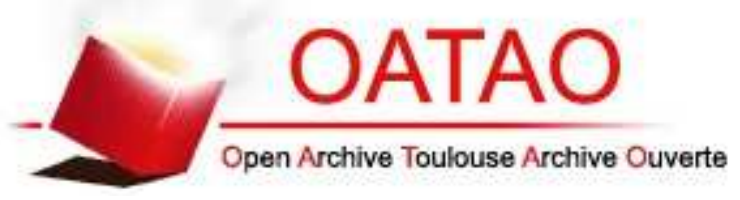

\section{Open Archive TOULOUSE Archive Ouverte (OATAO)}

OATAO is an open access repository that collects the work of Toulouse researchers and makes it freely available over the web where possible.

This is an author-deposited version published in : http://oatao.univ-toulouse.fr/ Eprints ID : 15056

The contribution was presented at :

http://www.pro-ve.org/

To cite this version : Qaeze, Fenemedre Drazine and Guillaume, Romain and Thierry, Caroline A collaborative model planning to coordinate mining and smelting furnace. (2015) In: 16th IFIP Working Conference on Virtual

Enterprises : Risks and Resilience of Collaborative Networks (PRO-VE 2015), 5 October 2015 - 7 October 2015 (Albi, France).

Any correspondence concerning this service should be sent to the repository administrator: staff-oatao@listes-diff.inp-toulouse.fr 


\title{
A collaborative planning model to coordinate mining and smelting furnace
}

\author{
Fenemedre Qaeze ${ }^{1}$, Romain Guillaume ${ }^{1}$, Caroline Thierry 1 \\ 1 University of Toulouse 2 Jean Jaures, \\ 5 Allée Antonio Machado \\ Laboratory of IRIT (Institut of Research in Informatic of Toulouse) \\ 31100 Toulouse, France
}

\begin{abstract}
In this paper, we are interested in the tactical planning problem of mines and smelting furnace. The problem concerns a set of mines with one smelting furnace. We are faced to a multi-actor's context for which a global optimization is not possible due to the independence of the services. This problem is solved using a set of local optimization model of mines bloc extraction and a model of smelting furnace. This paper begin with the state of the art related to the principal problems in mining process. It justifies the novelty of our work. Indeed, this paper aims to discuss on the impact of sharing information between downstream processes and upstream processes. Consequently, after the state of the art, the classical planning process using local optimization and the information sharing process are presented. In the following part, profits generated and related to different contexts: value-creation and approach are compared. At the end of the paper, conclusion and future extensions are presented.
\end{abstract}

Keywords: mining complex planning, information sharing, coordinated planning.

\section{Introduction}

Mining industry focuses on extraction and transformation of minerals principally in order to produce metals (nickel, iron, gold and copper). These metals are the result of complex processes implying different internal decision-making centers (DCs), themselves linked to other decision-making centers of the supply chain. In this paper, we are interested in the information sharing toward the DCs. Moreover, we focus on a particular key-information which is the value-creation of blocs.

In the literature, the problem of long term planning horizon of mining complex is well studied [1], [2], [3] and [4]. Nevertheless, to our knowledge, the middle/short term planning horizon is not well investigated [5] whereas it can help to face with uncertainty.

The most studied problems are the extraction problems. In the literature [6], it is noted that, due to the nature of the extracted material, a differentiation is made between the problems. Indeed, these different kinds of material have different characteristics depending upon different extraction processes. On the one hand there are the metallic 
ores (iron, copper), the nonmetallic minerals (sand, gravel) and the fossil fuels (coal) and on the other hand the petroleum and natural gas. In this paper we are interested on the metallic ore. The principal problems of the extraction models which aim to determine the ultimate open pit limit [8], [9], [10] and the determination of the sequence of extracted bloc [11], [12], [13] (see [6] for a revue) are well studied. [14], [15] propose a global optimization model (extraction and process). 
The principal problems studied are the extraction models: determination of the ultimate open pit limit and the determination of the sequence of extracted bloc (see [6] for a recent revue). [14], [15] propose a global optimization model (extraction and process).

The objective of extraction models is to maximize the net present value (valuecreation minus the cost of extraction and processing of blocs). Hence, the optimal solution depends on the value-creation of blocs which is difficult to estimate due to the uncertainty on grade elements, selling products price and cost of process which depends on the factory (process cost). [14], [2] and [4] propose models and/or algorithms to take into account the uncertainty on grade and [2] takes into account the uncertainty of prices. To optimize the cost of process, a global optimization approach is proposed by [14]. Nevertheless, a global optimization is not always possible since the mining and the furnace are independent DCs. In this paper we are interested in the coordination of the sequencing decision of bloc and the choice of the process in distributed context at the middle term planning horizon which, to our knowledge, has not been studied yet.

Firstly, the context and the problem are presented. Secondly, we detail the local optimization process. Then, the sharing information process and the possible information sharing (optimistic/ pessimistic/ average value-creation) is proposed. Then we present the simulation process and the analysis of the results. Finally, conclusion and perspectives are presented.

\section{Context and Problem}

In this paper we are interested in the coordination of the mining complex. The mining complex is composed of a set of mines which extract blocs and then deliver the extracted blocs to the smelting furnace (see Fig.1).

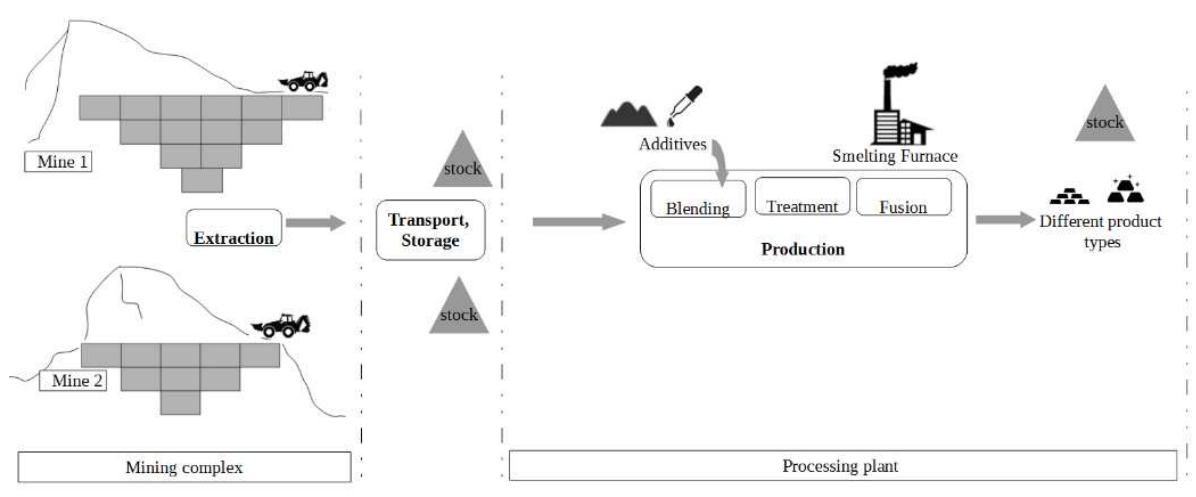

Fig. 1. Global mining complex 
Blocs are extracted from each mines, stored and then transported to the production and processing plant. At this first step of the internal supply chain, the extraction process is subject to important decisions of the downstream process. This process consists in determining:

- which bloc will be extracted or not

- the extraction plan (at which period the blocs will be extracted)

The objective of the plant is to satisfy a demand for the end of the planning horizon. The factory reserves the blocs from each mines and blends into one ore mixture. At this step dopants can be added to the ore mixture to satisfy the grade constraints of the smelting furnace. Then the mixture is treated and smelted. From the melted metal different products can be produced using different processes. The choice of proportion of the melted metal sent to a given process is called a production policy (which is defined for the planning horizon).

Noted that, the addition of dopants depends on the grade of the mixed ore mixture which depends on the mining extraction. Moreover the benefit of the factory is impacted by the pair ore mixture production policy since the grade of the element impacts the cost of process to obtain the final product. Nevertheless, the production policy can be chosen only if the sequence of bloc of each mine is known, which needs itself the information on value-creation of blocs. So, our problem is how to coordinate the decisions on the production and the extraction policies.

\section{Classical planning process using local optimization}

In this section we present the classical planning process, [8] [9] [10] [11] [12] [13], using local optimization for middle horizon planning (see Fig.2). The objective of this planning process is to determine the sequence of extracted bloc from each mine and the production policy to apply over whole the horizon. More precisely only one production policy can be applied through the horizon and we must ensure the adequacy between the bloc sequence and the production policy.

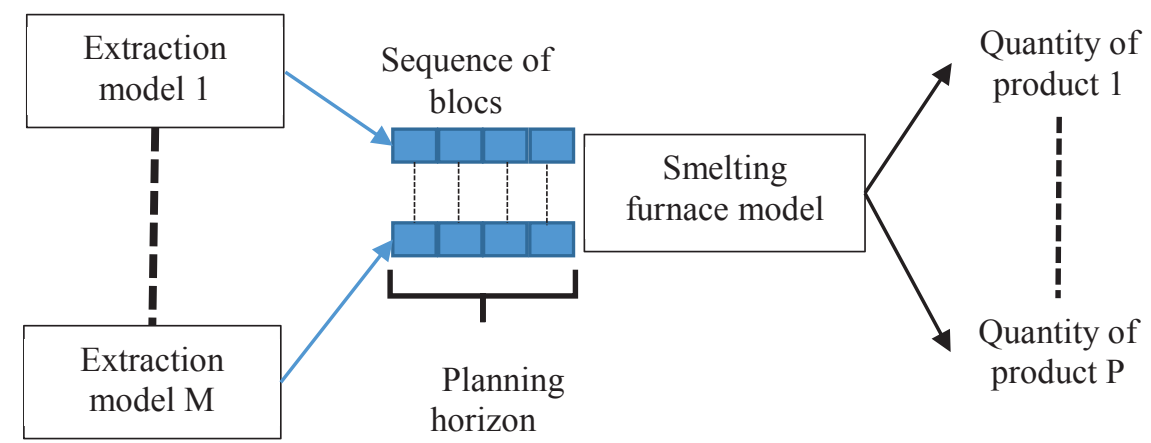

Fig. 2. Classical process in local approach 
The extraction model consists in maximizing the benefit for a horizon $t=1$ to $T$ under precedence constraints (a bloc cannot be extracted if another bloc has not been extracted before). The benefit is computed using the equation 1 where $V_{b}$ is the valuecreation of a bloc $b, C_{b}$ is the extracting cost of bloc $b$ and $x_{b, t}$ a binary variable which is equal to 1 if the bloc $b$ is extracted at period $t$ zero else. From those optimization, we obtain a sequence of blocs which will be the parameter of the smelting furnace planning model (see Fig.3).

$$
\sum_{b=1}^{B} \sum_{t=1}^{T}\left(V_{b}-C_{b}\right) x_{b, t} .
$$

The smelting furnace model determines the quantity of dopant to be added to the ore mixture in order to meet the element grade target imposed by the smelting furnace and the choice of the production policy. The production policy is a vector of $\%$ of the melted metal transformed into a product ( $\%$ for Product $1, \ldots, \%$ for Product $p$ ). Nevertheless, the quantity of product obtained depends on the production policy and the grade of elements of the melted metal (Fig.3).

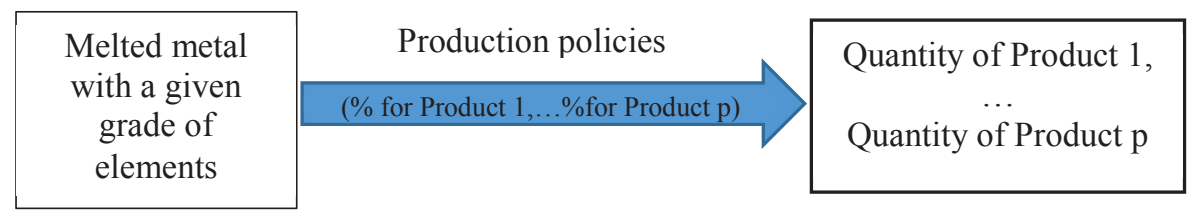

Fig. 3. Production policy

For instance, the mines of nickel can produce ferronickel and matte. To obtain the matte an iron removal is realized on the melted metal while for the ferronickel a desulphurization is realized. Indeed, the quantity of matte obtained depends on the percentage of nickel in the melt metal. The objective is to satisfy the demand of product while maximizing the profit (eq.2) where $B t_{p}$ is the selling price of product $p$ minus production cost of product $p, C I_{p}$ is the inventory cost of product $p, C B_{p}$ is the backordering cost of product $p, C d_{e}$ is the dopant cost of element $e, X_{p, t}$ is the quantity of product $p$ produced with the ore mixture extracted at period $t, B_{p}, I_{p}$ are respectively the backordering and the inventory of product $p$ at the end of horizon and $Q_{e, t}$ the quantity of dopant of element $e$ used for the ore mixture which is extracted at period $t$

$$
\sum_{t=1}^{T}\left(\sum_{p=1}^{P}\left(B t_{p} \times X_{p, t}-\left(C B_{p} \times B_{p}+C I_{p} \times I_{p}\right)\right)-\sum_{e=1}^{E} C d_{e} \times Q_{e, t}\right) .
$$

Hence, the optimization at this stage consists in determining: (1) the amount of dopant to be added to the ore mixture at each period and (2) the production policy knowing the sequence of blocs extracted from each mines. 


\section{Information sharing process}

The key information of the extracted model which does not depend on the mines is the value-creation of a bloc $b$ since it depends on the decision of smelting furnace (production policy) and of the quality of the blocs from the other mines since the ore mixture has to respect some smelting furnace constraints. To help the mines to estimate the value-creation of a bloc, we propose that the mines share information with the smelting furnace planning to refine the estimation of value-creation of blocs. The questions to be answered are:

1. Which information to be shared (section 4.1)?

2. How to estimate the value-creation (section 4.2)?

\subsection{Framework of information sharing}

The extraction decision-maker (DM) communicates the quality of the extracted blocs (grade of elements) to the smelting furnace DM. From this information the smelting furnace DM computes the value-creation of a bloc taking into account the possible production policy and the respect of smelting furnace constraints (see Fig.4). This value-creation is communicated to the extraction DM.

In the following section, 4.2, we describe how to valuate an extracted bloc taking into account the production decision.

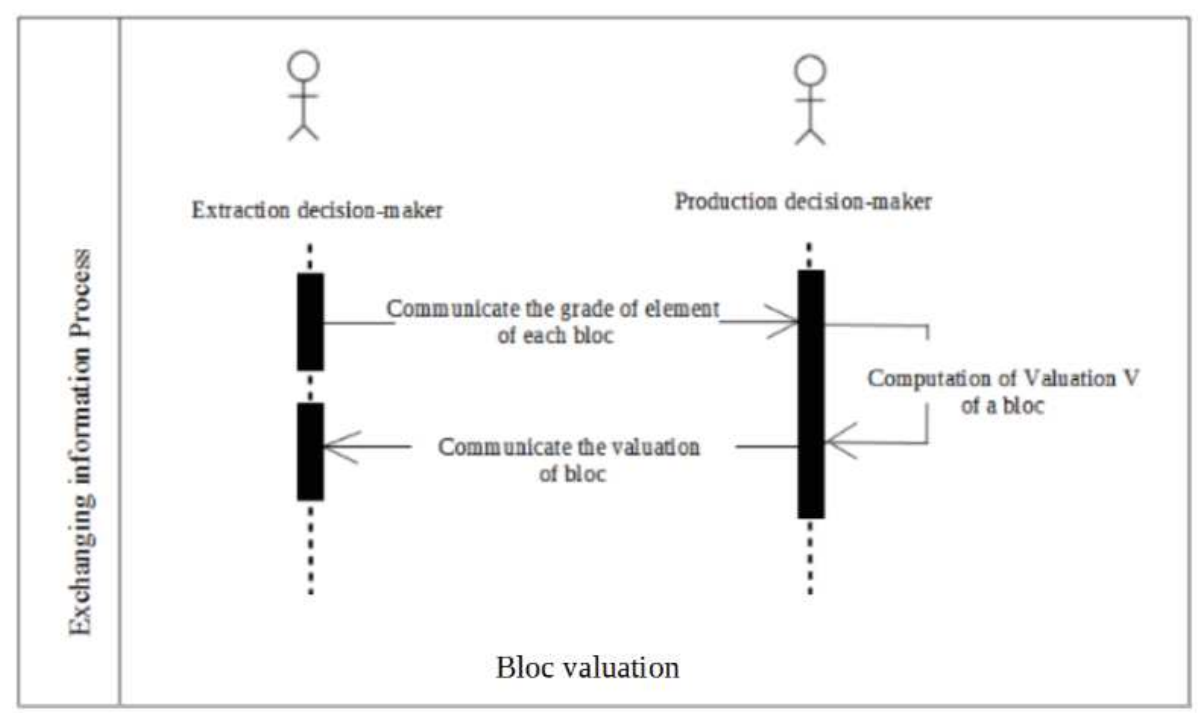

Fig. 4. Sharing information process

\subsection{Estimation of value-creation taking into account production decision}


The objective of this study is to evaluate the impact of estimation value-creation of a bloc $b$ under uncertainty on the production policies. In this section, we propose three different ways for computing the value-creation of a bloc $b$. The objective of this study is to evaluate the impact of estimation value-creation of a bloc $b$ under uncertainty on the production policies. The first one is a classical way to aggregate the uncertainty using the average aggregator (noted $V_{b}^{a v}$ for a bloc $b$ ) (implicitly it is considered that each production policy has the same probability to be chosen). The second one is the pessimistic evaluation (noted $V_{b}^{\text {pess }}$ for a bloc $b$ ). In other words, we suppose that we will use the less profitable policy for this bloc. And, the last one is the optimistic evaluation (noted $V_{b}^{o p}$ for a bloc $b$ ). In this case, we suppose that we will use the most profitable policy for this bloc. Equation (3), (4) and (5) are used to compute respectively $V_{b}^{a v}, V_{b}^{\text {pess }}$ and $V_{b}^{o p}$ with $p l$ the index of production policy, $Y_{b, p l, p}$ the quantity of product $p$ for production policy $p l$ produced from the bloc $b$ and $Q_{e, b}$ the quantity of dopant of element $e$ required to satisfy the smelting furnace constraints.

$$
\begin{gathered}
V_{b}^{a v}=\frac{\sum_{p l=1}^{P l}\left(\sum_{p=1}^{P} B t_{p} \times Y_{p, p l, b}-\sum_{e=1}^{E} C d_{e} \times q_{e, b}\right)}{P l} . \\
V_{b}^{p e s s}=\min _{p l \in\{1, \ldots, P l\}} \sum_{p=1}^{P} B t_{p} \times Y_{b, p l, p}-\sum_{e=1}^{E} C d_{e} \times Q_{e, b} . \\
V_{b}^{o p}=\max _{p l \in\{1, \ldots, P l\}} \sum_{p=1}^{P} B t_{p} \times Y_{b, p l, p}-\sum_{e=1}^{E} C d_{e} \times Q_{e, b} .
\end{gathered}
$$

We note that for these valuations, we consider the blocks separately from each other since the DM of smelting furnace does not know the sequence of bloc and neither with which bloc of the other mines it will be blended.

\section{Description and Analysis of the test}

\subsection{Description of the data}

To analyze the impact of the estimation of the value-creation, we have simulated the three possible value-creations (optimistic, pessimistic and average) and computed the global optimization for 50 instances for 3 sizes of horizon with a mines complex composed of two mines. 


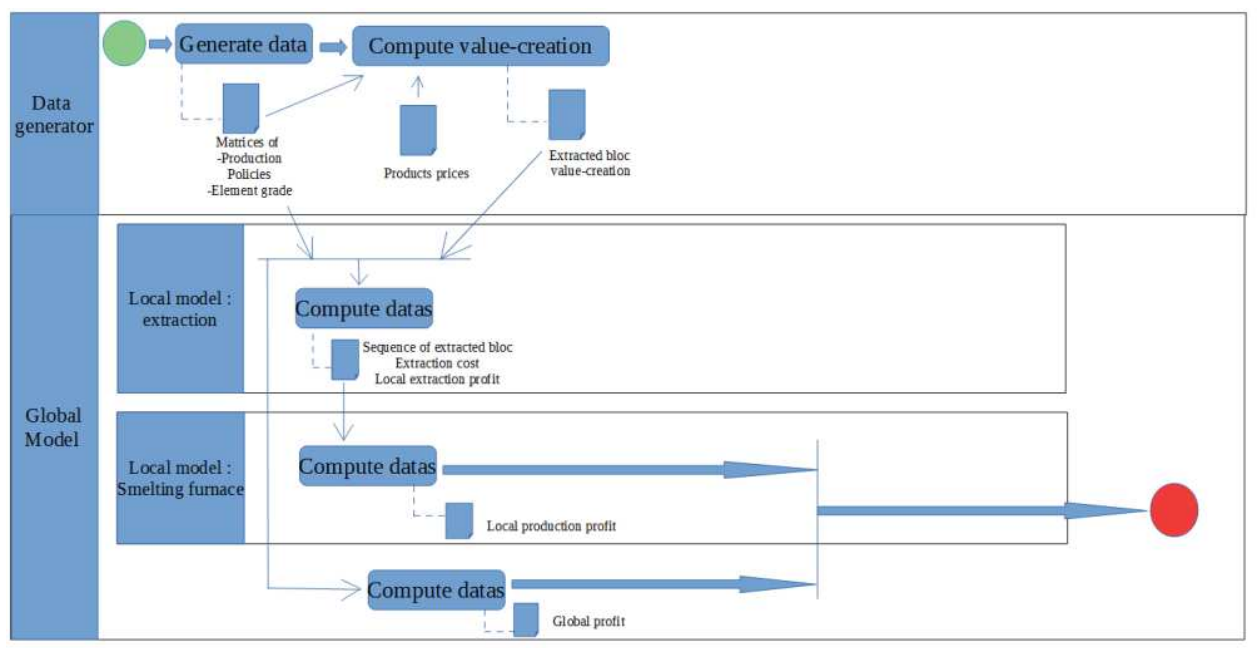

Description of the test Process

Fig. 5. Test process

The process of test is detailed in Fig.5. For each test, we randomly generate data. More precisely, the matrix that characterizes production policy is generated for each test. This matrix gives the quantity of each product $p$ produced for a production policy $p l$ of melded metal satisfying the characteristics on grade of elements. Another matrix that characterizes the grade of elements in an extracted bloc is also generated. This matrix assigns a percentage of each element $e$ at each bloc $b$. From these matrices, we compute the three proposed value-creations (a verifier) of blocs using eq. 3 , eq. 4 and eq.5

A matrix with the value-creation of the blocs is an input of the local model of extraction. The local model of extraction computes the extraction cost and the sequence of the extracted blocs. The sequence of the extracted blocs is an input for the local model of smelting furnace. This local model computes the profit of the production and selling activity. To compute the global profit, we subtract the cost of the extracting blocs to the profit of the production and selling activity (eq.6).

$$
\begin{gathered}
\sum_{t=1}^{T}\left(\sum_{p=1}^{P}\left(B t_{p} \times X_{p, t}-\left(C B_{p} \times B_{p}+C I_{p} \times I_{p}\right)\right)-\sum_{e=1}^{E} C d_{e} \times Q_{e, t}-\right. \\
\left.\sum_{b=1}^{B} C_{b} \times x_{b, t}\right) .
\end{gathered}
$$

To evaluate if it is possible to increase the performances, we compute the optimal solution using a global optimization model which determines simultaneously the extraction sequence, the addition of dopant and the production policy in order to maximize the objective function defined by the equ. 6 . 


\subsection{Presentation and analysis of the result}

The Tab. 1 shows the percentage of gain to use the optimistic evaluation rather than pessimistic, pessimistic rather than average and optimistic rather than average. We can see that optimistic and a pessimistic value-creations are both better than anerage value-creation. Which is in contradiction with naive way to aggregate the uncertainty.

More precisely, for the different value-creations and for 50 tests (whatever the problem size), we only have 2 tests in which an average value-creation generates the best profit, so optimistic and pessimistic value-creations are both better at $96 \%$ to the average. It is difficult to determine the best value between the optimistic and pessimistic value-creations since the results are approximately the same.

Table 1. Average Value-creation, Optimistic Value-creation and Pessimistic Valuecreation.

\begin{tabular}{r|lll} 
& Maximum & Average & Minimum \\
\hline Optimistic/Pessimistic & $23.12 \%$ & $0.79 \%$ & $-19.83 \%$ \\
\hline Pessimistic/Average & $30.42 \%$ & $5.28 \%$ & $-20.82 \%$ \\
\hline Optimistic/Average & $24.96 \%$ & $5.88 \%$ & $-9.47 \%$ \\
\hline
\end{tabular}

In a second step, we compare the three local approaches with the optimum in which the profit is generated by the global approach. Tab. 2 shows the percentage of gain by using the global optimization rather than one of the local evaluation with different value-creations. It can be noted that, for some tests, the difference between profits generated with an optimistic value-creation (respectively pessimistic value-creation) and global approach is significant (see the maximum of percentage of difference in table $2: 24,73 \%$ and $23,18 \%$ ). In order to reduce the maximum of percentage of difference between local approaches and global approach, an improvement should be made on the optimistic and pessimistic value-creations. This improvement is presented in future works.

Table 2. Comparison between local approaches and optimum (global approach).

\begin{tabular}{r|lll} 
& Maximum & Average & Minimum \\
\hline Global/ Optimistic & $24.73 \%$ & $1.56 \%$ & $0 \%$ \\
\hline Global /Average & $34.27 \%$ & $7.10 \%$ & $0 \%$ \\
\hline Global/Pessimistic & $23.18 \%$ & $2.16 \%$ & $0 \%$ \\
\hline
\end{tabular}

It can be observed that optimistic and pessimistic value-creations of extracted blocs generate the highest profits. These generated profits can be considered as near-optimum solutions. As a global approach is not allowed in our context of independent DC that is why to avoid this challenge, local approaches can be preferred. 


\subsection{Discussion of a general applicability of the result}

To catch a general applicability of the results, the three principal questions to ask is: how to optimize local approach in order to generate profits that can be considered as near-optimum solutions? Consequently, what information to be shared? And how to compute this information? It will be interesting to find a way of collaboration for the different decision makers, for example using the mining complex network. In order to calculate, the value creation or the bloc to be extracted, the downstream process communicates its needs to the upstream process.

\section{Conclusion and Perspectives}

To summarize, we have presented previously the problem and the importance of sharing information to optimize the local approach. The description and the analysis of the test presented previously, showed that a good value-creation of the extracted blocs increases profit. Moreover, we stressed that an optimistic and a pessimistic evaluation aggregation of uncertainty is better then the naïve way. /the naive way to aggregate the uncertainty on the production policy can be far from the optimistic and pessimistic evaluation/. In this paper we have investigated the collaboration between each mines with the smelting furnace. As a perspective of a future paper, we are studying uncertainty resulting from the impact of the coordination of the different mines. We call this uncertainty, vertical uncertainty. This coordination between the different mines leads to meet an ore mixture degree which leads to the production of best profit product. Furthermore, the coordination of the blocs extraction from the set of mines could be done in order to minimize the production cost. Thereby, smelting furnace DC would guide all the mines DM by recommending the type of blocs (in terms of grade of element) to be extracted from each mine during the horizon.

\section{References}

1. Masoud Soleymani Shishvan and Javad Sattarvand: Long term production planning of open pit mines by ant colony optimization, (2014)

2. Koushavand Behrang, Askari-Nasab Hooman and Deutsch Clayton V: A linear programming model for long-term mine planning in the presence of grade uncertainty and a stockpile, (2014)

3. J.Zhang and R.Dimitrakopoulos: Optimising a Mineral Supply Chain under Uncertainty with Long-term Sales Contratcts. OREBODY MODELLING AND STRATEGIC MINE PLANNING SYMPOSIUM 2014 / PERTH, WA, 24-26 Novembre (2014) 
4. MWA Asad and R Dimitrakopoulos: Implementing a parametric maximum flow algorithm for optimal open pit mine design under uncertain supply and demand, (2012)

5. Li Shu-xing, KNIGHTS Peter: Integration of real options into short-term mine planning and production scheduling, (2009)

6. A.Newman: A Review of operations research in Mine Planning, pp.222-245, INFORMS, (2010)

7. Gholamnejad and Osanloo: Using chance constrained binary integer programming in optimising long term production scheduling for open pit mine design, Volume 116, pp. 5866, (2007)

8. K.Dagdelen: Open Pit Optimization - Strategies of Improving Economics of Mining Projects through Mine Planning, (2001)

9. A.Leite, R.Dimitrakopoulos: Stochastic optimization model for open pit mine planning: application and risk analysis at copper deposit, (2007)

10. J.Amaya, D.Espinoza, M.Goycoolea, E.Moreno, T.Prevost, E.Rubio: A scalable approach to optimal block scheduling, (2009)

11. F.Alvarez, J.Amaya, A.Grienwank, N.Strogies: A continuous framework for open mine planning, (2010)

12. H. Askari-Nasab, K. Awuah-Offei: Opem pit optimisation using discounted economic block values (2009)

13. R.Dimtrakopoulos and E.Goodfellow: Stochastic optimization of Mineral Value Chains Developments and Applications for the Global Optimisation of Mining Complexes with Uncertainty. OREBODY MODELLING AND STRATEGIC MINE PLANNING SYMPOSIUM 2014 / PERTH, WA, 24-26 Novembre (2014)

14. Mustafa Kumral: Multi-period mine planning with multi-process routes, (2013) 